\title{
Wooden Rockers Were Open Mould for Mudbrick or Concrete Ones
}

\author{
Akio Kato \\ Department of Mathematics and Physics, Faculty of Science, Kanagawa University, Hiratsuka, Japan \\ Email: akiokato1521@gmail.com
}

How to cite this paper: Kato, A. (2021). Wooden Rockers Were Open Mould for Mudbrick or Concrete Ones. Archaeological Discovery, 9, 151-164.

https://doi.org/10.4236/ad.2021.93008

Received: March 31, 2021

Accepted: May 31, 2021

Published: June 3, 2021

Copyright $\odot 2021$ by author(s) and Scientific Research Publishing Inc. This work is licensed under the Creative Commons Attribution International License (CC BY 4.0).

http://creativecommons.org/licenses/by/4.0/

\begin{abstract}
The true purpose of a wooden "rocker" from a foundation deposit in the tomb of Queen Hatshepsut at Dier el-Bahri is proposed that it was an open mould for a mudbrick or concrete rocker. The solid rockers produced by such a mould have grooves that act as rope channels so that they can be attached to a stone (or sledge under the stone) by ropes to roll or turn the stone easily. We proposed how the wooden rocker could be used to produce solid rockers, then tested this method experimentally to get mudbrick or concrete rockers with grooves.
\end{abstract}

\section{Keywords}

Rocker, Mould, Mudbrick

\section{Introduction}

It has been long wondered about the true purpose of a wooden appliance called "rocker" or "cradle" (Figure 1) excavated from a foundation deposit (Figure 2) in the tomb of Queen Hatshepsut at Dier el-Bahri (the New Kingdom, circa 1550 to circa $1069 \mathrm{BC}$ ). We here propose its new feasible purpose that it was an open mould for a mudbrick or concrete rocker, and the solid rockers produced by this mould would be used in maneuvering heavy stones.

It was assumed hitherto that the excavated rockers as in Figure 1 and Figure 2 are "models" of some masonry tools because they are small and look too fragile to support any heavy stone. But our opinion is that they are full-size, usable tools, not models. Note that a usable brick mould of Figure 3 was also excavated from a foundation deposit in the tomb of Queen Hatshepsut, and this brick mould is almost the same size as a rocker in Figure 1, as can be well observed in Figure 4. These tools were votive objects placed in pits for foundation ceremony 
so that tools of small size would be chosen in particular, and it would be sincere to select usable tools (rather than "models") as votive objects. Note that our observation does not deny bigger wooden rockers. It is known that big bricks of dimensions about $40 \mathrm{~cm} \times 20 \mathrm{~cm} \times 15 \mathrm{~cm}$ were made during the New Kingdom (Hassaan, 2017) so that there must be the corresponding brick moulds much bigger than Figure 3. Similarly, it would be quite natural to assume that there were wooden rocker moulds bigger than the ones in Figure 1 or Figure 2.

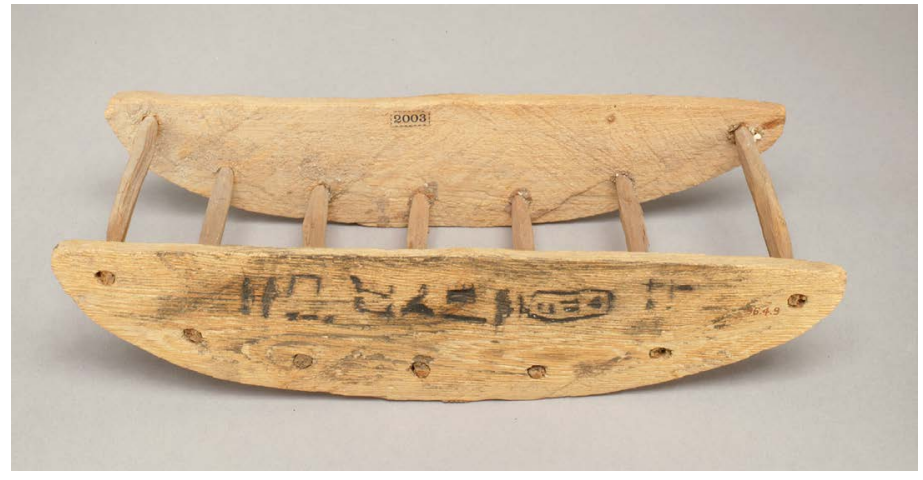

Figure 1. Rocker from a foundation deposit in the tomb of Queen Hatshepsut at Dier el-Bahri, with dimensions: L. $23.6 \mathrm{~cm}$; W. $10.5 \mathrm{~cm}$; H. $5.1 \mathrm{~cm}$.

(https://www.metmuseum.org/art/collection/search/547563).

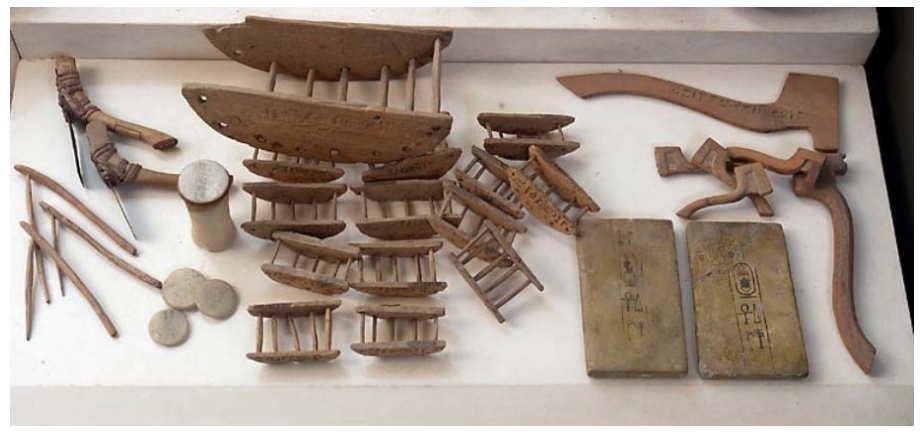

Figure 2. Votive objects from a foundation deposit in the tomb of Queen Hatshepsut at Dier el-Bahri.

(https://www.louvre.fr/en/oeuvre-notices/foundation-deposit-temple-deir-el-bahri).

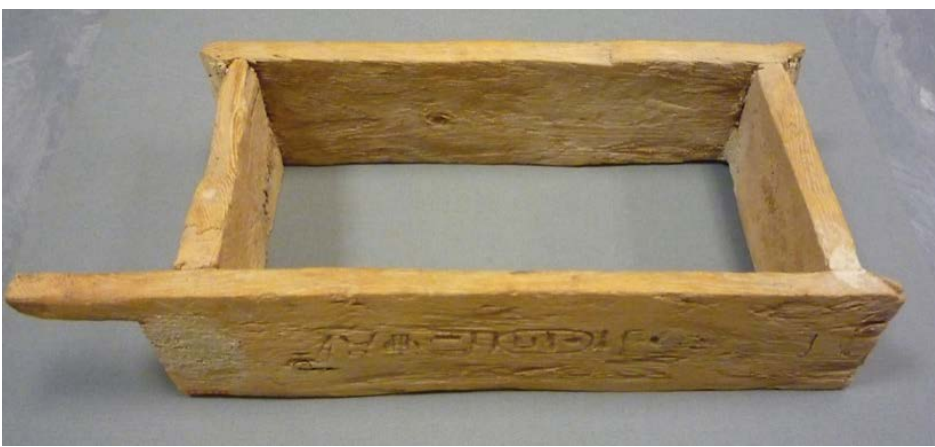

Figure 3. Rectangular wooden mould for mudbrick from a foundation deposit in the tomb of Queen Hatshepsut at Dier el-Bahri. The longest edge with the handle is of length $28 \mathrm{~cm}$. (https://www.metmuseum.org/art/collection/search/547576). 


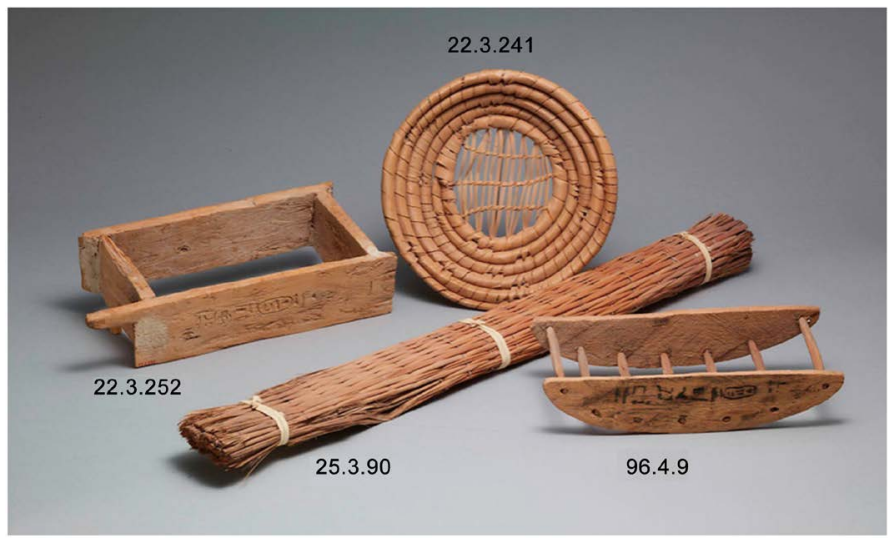

Figure 4. Various tools from a foundation deposit in the tomb of Queen Hatshepsut at Dier el-Bahri. (https://www.metmuseum.org/art/collection/search/547563).

The rocker of Figure 1 has the structure as illustrated in Figure 5 which is compounded of a couple of wooden boards with curved bottom edges, AEB and $\mathrm{DFC}$, interconnected with several round wooden bars. The top ABCD is wide open, and this feature strongly supports our view that such a hollowed rocker would be an "open" mould for a solid rocker. Observe that the wooden rocker Figure 5 can mould a solid rocker as in Figure 6, like a plano-convex brick, with grooves on its convex side. Details about how to produce such a solid rocker using clay or concrete will be explained in $\$ 3$.

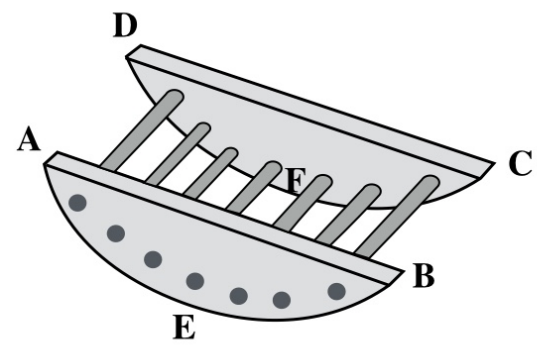

Figure 5. Illustration of a rocker.
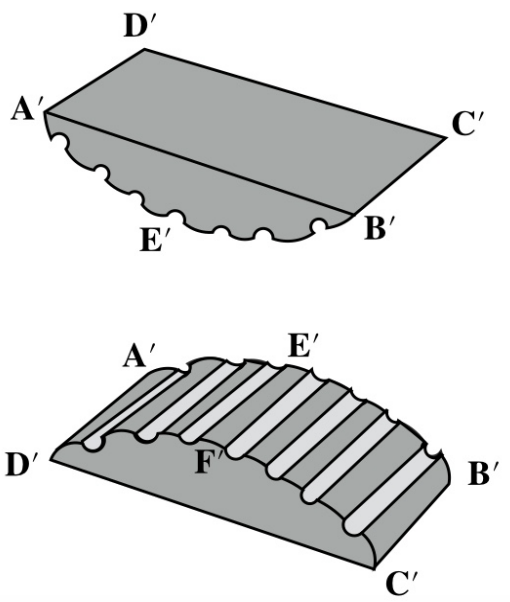

Figure 6. Solid rocker to be produced by the mould of Figure 5. 


\section{Solid Rockers with Grooves as an Intermediate Device between a Heavy Stone and Ropes}

In our former papers, (Kato, 2020) and (Kato, 2021), we have already introduced "rocker made of stone" like Figure 7 which we assumed to be obtained by chamfering a stone of cuboid. In (Kato, 2020) we described it as "trapezoidal prism" and showed how such a trapezoidal prism can be used in rotating or in turning a heavy stone (Kato, 2020). Further, in (Kato, 2021) we employed such rocker as one of principal means to maneuver heavy long obelisks (Kato, 2021). We note Fonte (Fonte, 1998) called such a rocker of semicylinder "quarter circle" and showed how it could be used in rotating a heavy stone by placing its flat side on the ground. Our usage is an upside down version of Fonte's, that is, we place its convex side on the ground so that its flat side can touch the stone as illustrated in Figure 8.
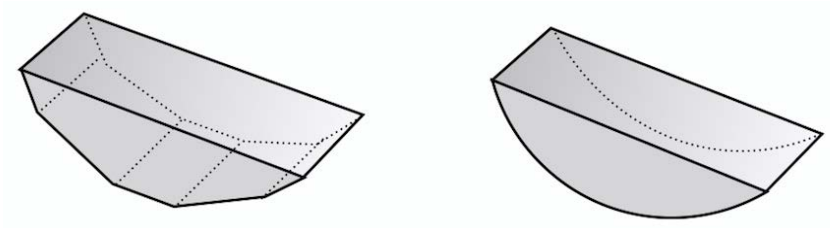

Figure 7. Rockers made from stones of cuboid by chamfer.
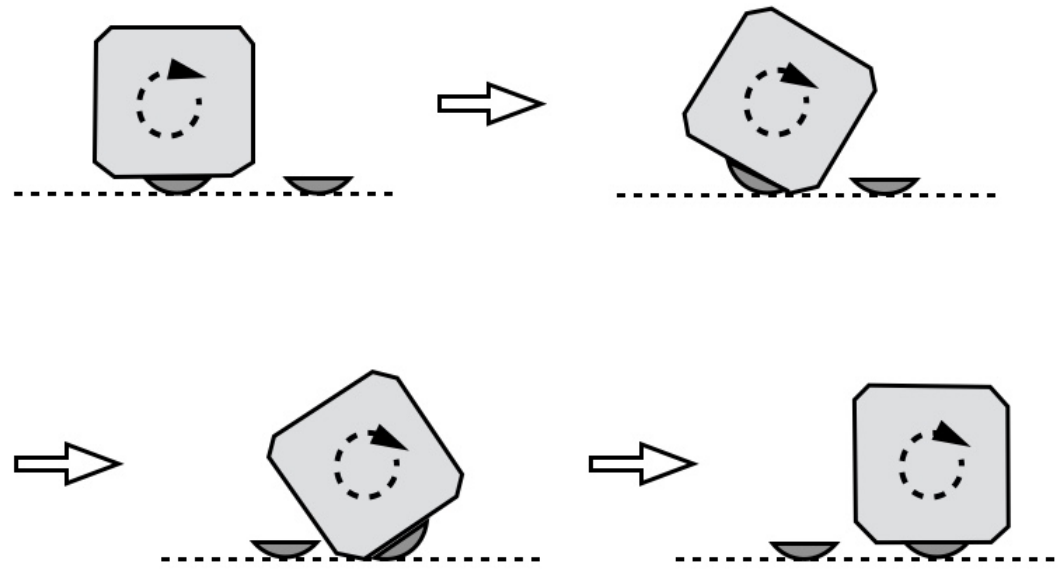

Figure 8. How to use rockers of stone in rotating a heavy stone.

Now we show how the solid rocker of Figure 6 can be employed in maneuvering a heavy stone. A distinct advantage of the moulded rocker Figure 6 over the stone one Figure 7 is that the former has the grooves, thanks to the wooden bars of the mould. These grooves are quite useful as they can act as rope channels, and a rope would not be crushed between the rocker and the ground if it is engaged in the groove cf. (Pierattini, 2019). Figure 9 and Figure 11 illustrate examples how the rockers could be attached to a stone in order to roll it like Figure 10. (There would be many other ways of setting rockers and ropes around the stone.) What is important here is that we "can" attach rockers to a stone thanks to grooves. Observe additionally that these attached rockers protect 
the surfaces of the stone during rotation, and this fact would be quite important and necessary in particular when the stone was already decorated with inscriptions and colors. Note further that ropes (not deeply embedded) in the groove would act somewhat as a cushion like a rubber of wheel to protect the rocker. Thus, ropes protect rockers protect the stone. The illustration of Figure 11 shows the case of an octagonal column, and many of such columns would be produced as predecessors of cylindrical columns in temples. The rocker can be fastened also to a timber like Figure 12. And this way of attaching rocker can be applied for example as in Figure 13 and Figure 14. The two rockers in Figure 13 make the bottom of sledge convex, and the one rocker in Figure 14 makes it easy to turn a heavy stone. In the foundation deposit of Figure 2, we can see many very short wooden rockers which would have produced solid rockers of length about $10 \mathrm{~cm}$, portable. Such small rockers would be used as in Figure 14. It is explained in (Isler, 2001) that: "A block of stone that is difficult to turn which is lying on a flat surface can readily be turned when imbalanced by having a small square of hardwood placed under its flat bedding face." The role of the small rocker in Figure 14 is the same as such a small square of hardwood. Note that the top of such a small rocker is almost a square. Of course, another use of such short rockers of half cylinder could be like in Figure 8 or Figure 10 to roll a cubic stone of side length about half a meter or less. Note that a cubic stone of side length half a meter looks small but weighs about 300 $\mathrm{kg}$, very heavy!

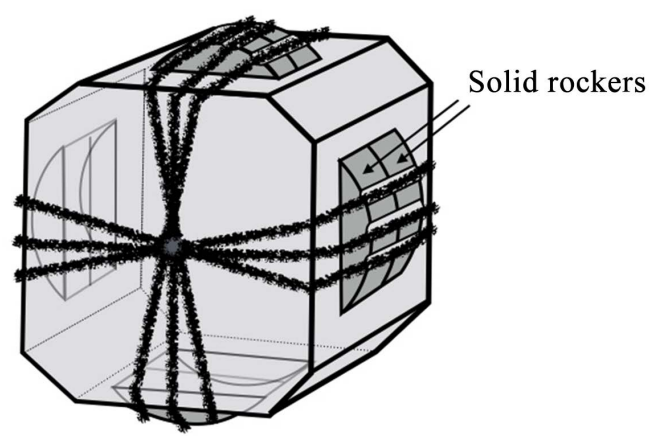

Figure 9. Example of attachment of solid rockers by ropes: Eight rockers in total with two on each of four sides.

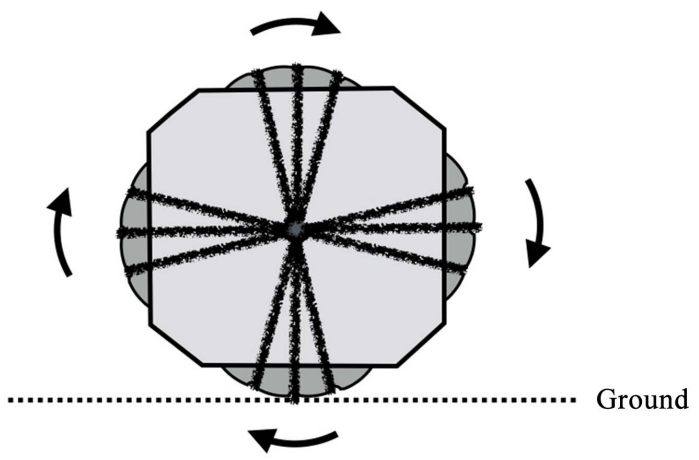

Figure 10. Stone of Figure 9 can be rolled easily. 


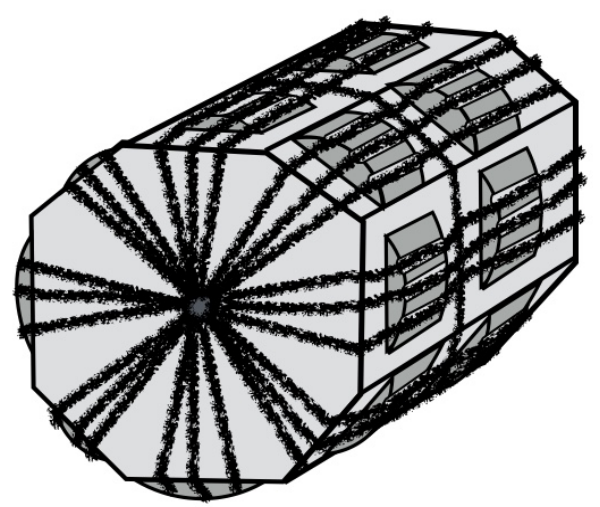

Figure 11. Example of attachment of solid rockers to an octagonal column by ropes.

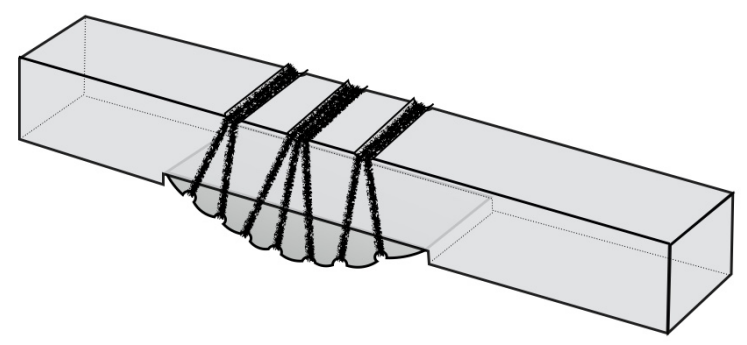

Figure 12 . How to attach the rocker under a timber.

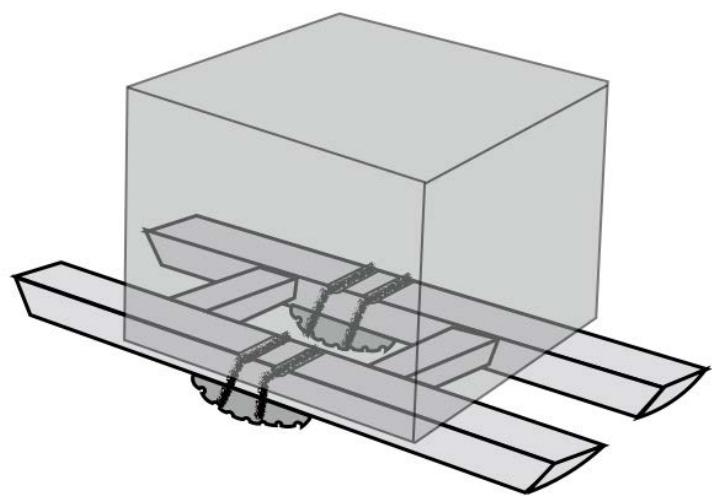

Figure 13. Affixing rockers under a sledge to make its bottom convex.

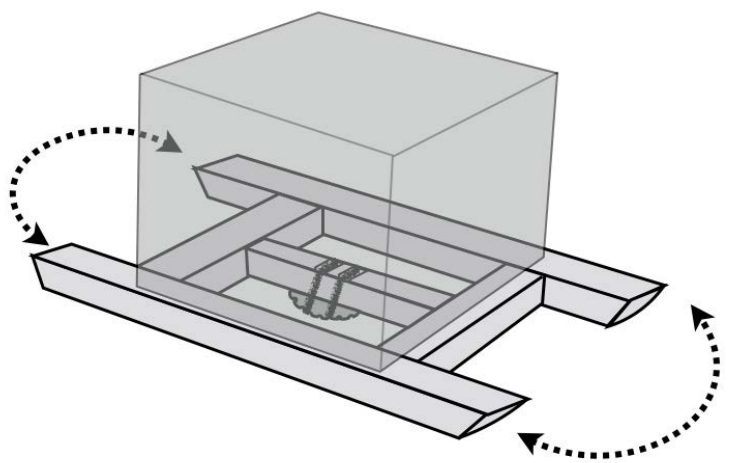

Figure 14. Use of a small rocker to turn a stone. 


\section{How to Make Solid Rocker}

Let us show how the wooden rocker can be used as a mould to produce a solid rocker, made of clay or concrete. First, let us consider the case of viscous clay to make a mudbrick rocker. Prepare a loaf of well-compressed clay of almost the same size as the wooden rocker. (Quite incidentally, we may use the wooden brick mould like Figure 3 in order to make such a well-compressed clay clot.) Press the loaf of clay into the wooden rocker as (1) in Figure 15, where some thin cloth is laid in order to shape the clay. Using a flat piece of wood, scrape the excess clay off of the rocker. Sun-dry the clay on the board as (2) in Figure 15 for some time until it is dried somewhat. Then remove carefully the wooden rocker by lifting it as in (3) of Figure 16. The laid cloth would help to separate the clay from the wooden rocker. Finally sun-dry well the moulded clay, placing it in the form of (4) of Figure 16 in order to be sun-dried effectively. This process of Figure 15 and Figure 16 is what we believe to be a standard one, and there would be many variants. We note that the mudbrick rocker could be very strong when good clay was used like the soil of Egypt: (Maspero, 1895). "The soil of Egypt, periodically washed by the inundation, is a black, compact, homogeneous clay, which becomes of stony hardness when dry". It is also well known that adding plant straw strengthens clay products (Hassaan, 2017).

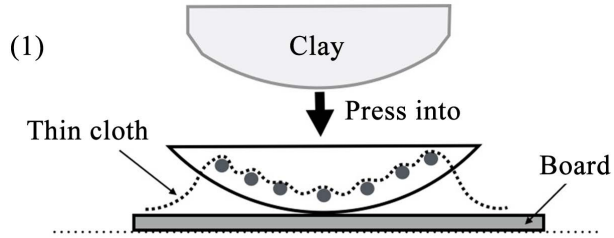

(2)

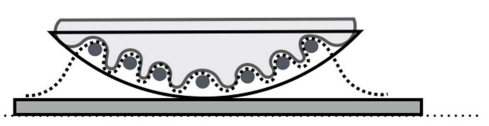

Figure 15. Pressing the loaf of well-compressed clay into the wooden rocker (Side view).

(3)

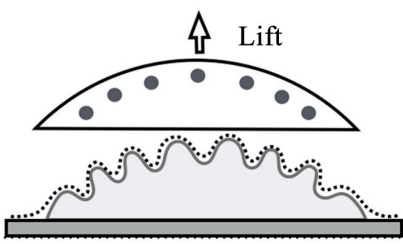

(4)

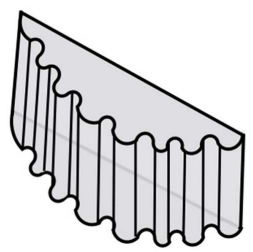

Figure 16. Sun-dry. 
We remark that the shape of the solid rocker thus obtained has vulnerable thin spots near the two acute edges as shown in Figure 17, but it can survive even if the two edges were chipped, and the shortened rocker with flat ends as in Figure 17 could be stronger than the original one. This vulnerability is due to the shape, not the material, and it is easy to modify the shape of mud-brick rocker. Moreover, the length of the mud-brick rocker can be adjusted by cutting off acute ends, and the flat ends work effectively in connecting rockers as shown in Figure 18. So, we may conclude that it would be better to aim at making mud-brick rockers with flat ends rather than acute ends.

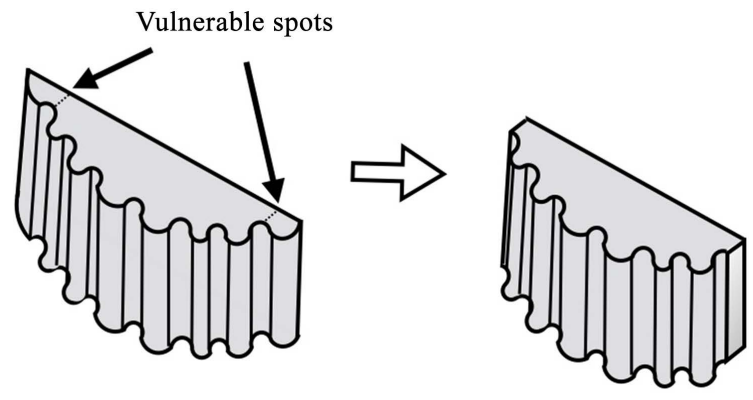

Figure 17. The solid rocker in (4) of Figure 16 can survive even if the two edges were chipped.

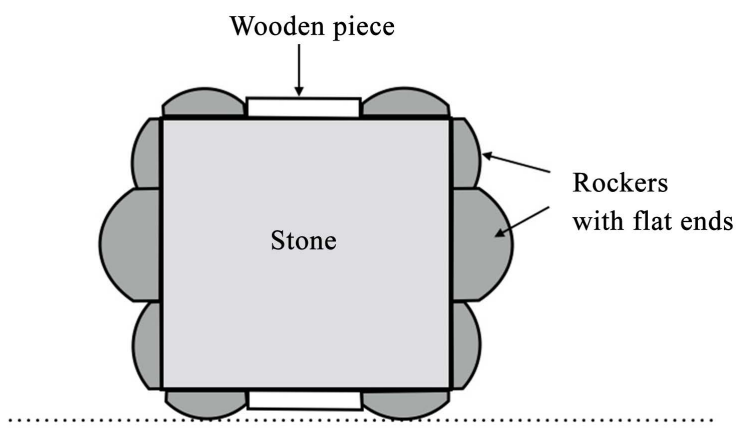

Figure 18. How to connect rockers (Side view).

The case of concrete would be almost the same as that of clay if we replace "pressing clay into the wooden rocker" in Figure 15 with "pouring concrete into the wooden rocker." Since concrete is not so viscous as clay, we propose to insert some bendable thin wooden plate (or some bark), instead of "thin cloth," as illustrated in Figure 19. Recall that solid rockers moulded by the wooden rocker are to be affixed on the faces of a heavy stone as explained in $\$ 2$. Hence they should be light enough to be portable. For such purpose, it would be preferable to produce an "arched" type of rockers, and this can be done easily by pressing a short wooden cylinder onto the center of the surface of the poured concrete, as shown in Figure 20. Then we can get an arched concrete rocker like Figure 21. Of course, this is lighter than the non-arched one, yet it remains to be strong because of its arch structure. Though we have used the general term "concrete", the concrete the ancient Egyptian used seems to be gypsum mortars or mortars of 
lime and mud, which is a bit different from our modern Portland cement with sand. So, precisely speaking, we better replace our term "concrete" with "mortars of lime and mud," and the resultant is a "mud-concrete" rocker. See (Arooz \& Halwatuna, 2018) about the strength of "mud-concrete".

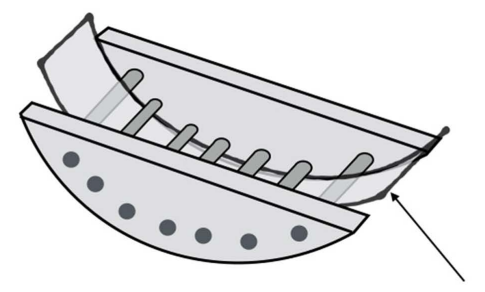

Bendable thin wooden plate

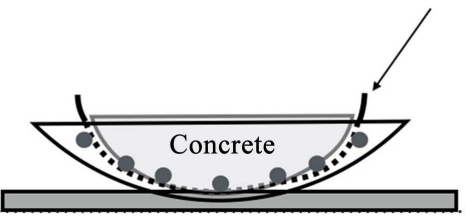

Figure 19. Mould to produce a concrete rocker.

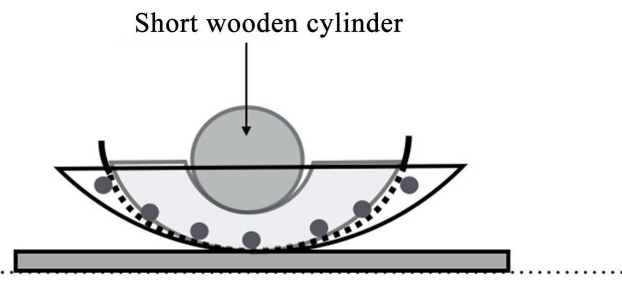

Figure 20. How to produce an arched rocker.

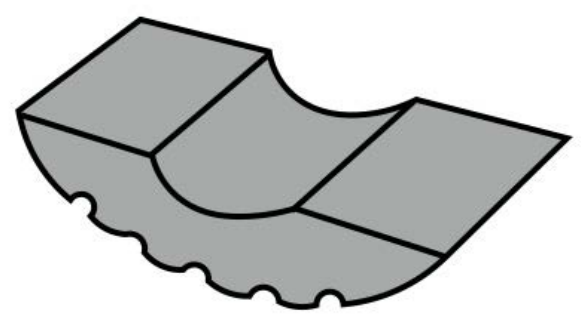

Figure 21. Arched rocker produced by the method of Figure 20.

\section{Experiments}

We have tested our theory of producing solid rockers by experiment, though we had no experience even of making homemade bricks. First, we made a wooden rocker almost of the same size as the excavated one Figure 1 and produced mudbrick rockers following the procedure of Figure 15 and Figure 16 using clay. The result is Figure 22 and Figure 23. (In producing the mudbrick rocker of Figure 22 we could dispense with the supplementary cloth described in Figure 15 as we could use a good clay clot well compressed.) Next, following the procedure of Figure 19 and Figure 20 we used Portland cement with sand to make the arched concrete rockers of Figure 24. We experimentally made also 
the concrete rocker Figure 25 with holes instead of grooves applying the method similar to Figure 19, a bit lowering the bendable wooden plate. But, we can see that rockers with grooves rather than holes are much easier to be handled with, mainly because a rope thicker than the width of the groove can be used for the groove, but this is not the case for the hole. So, we may conclude that rockers with holes would not be used actually, though they could be made theoretically. We also experimented how our rockers can be attached to timbers by ropes, as exhibited in Figure 26 and Figure 27.

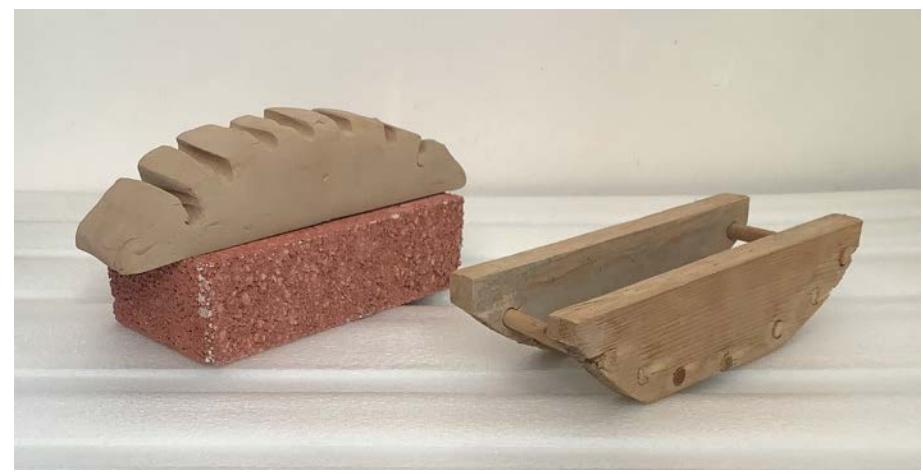

Figure 22. Mudbrick rocker (on the red brick of dimensions $20 \mathrm{~cm} \times 10 \mathrm{~cm} \times 6 \mathrm{~cm}$ ) produced by our wooden mould (right).

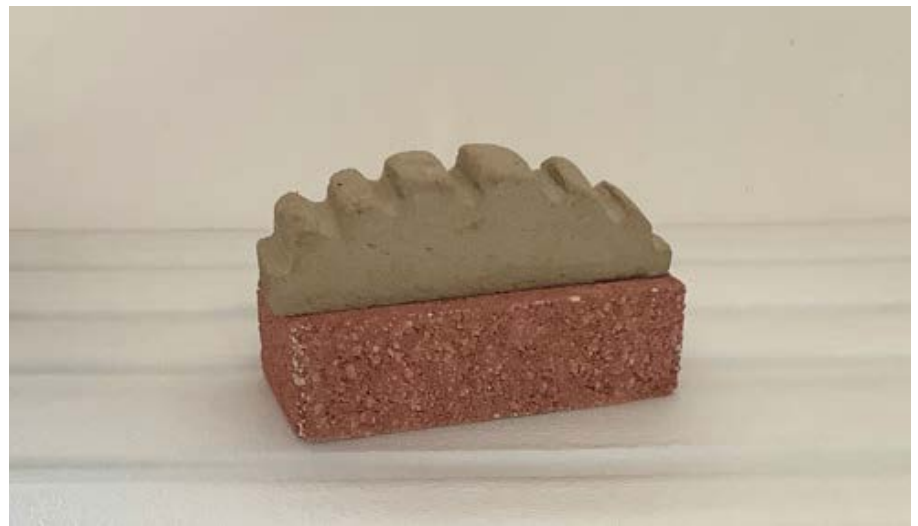

Figure 23. Mudbrick rocker with flat ends.

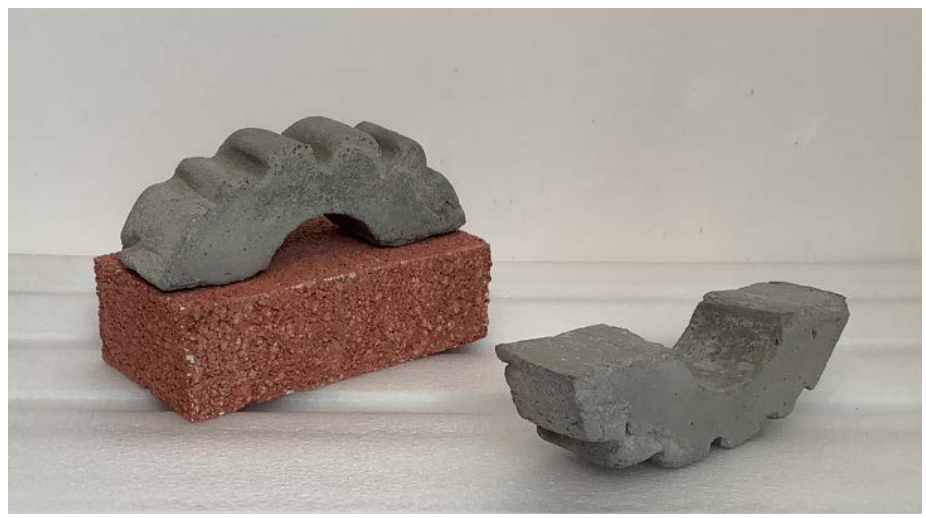

Figure 24. Arched concrete rockers. 


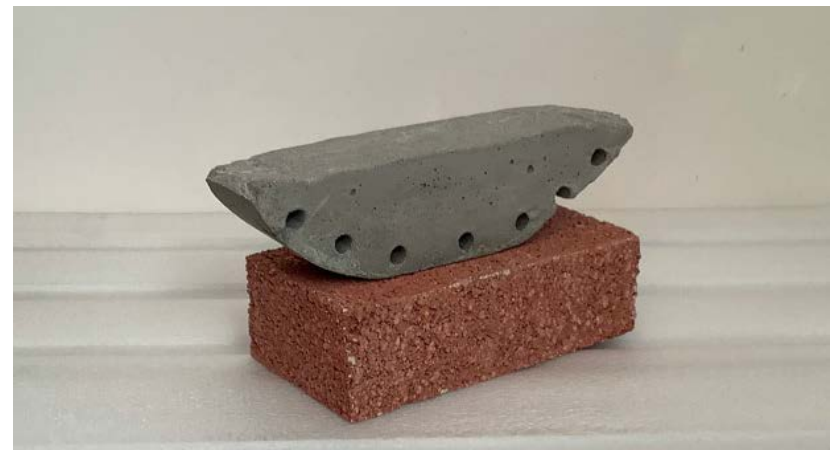

Figure 25. Concrete rocker with holes.

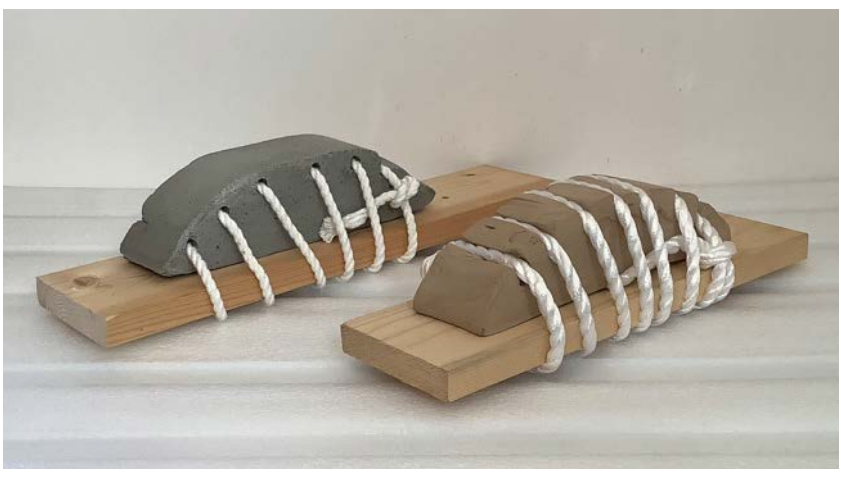

Figure 26. Rockers of Figure 22 and Figure 25 attached to timbers by ropes.

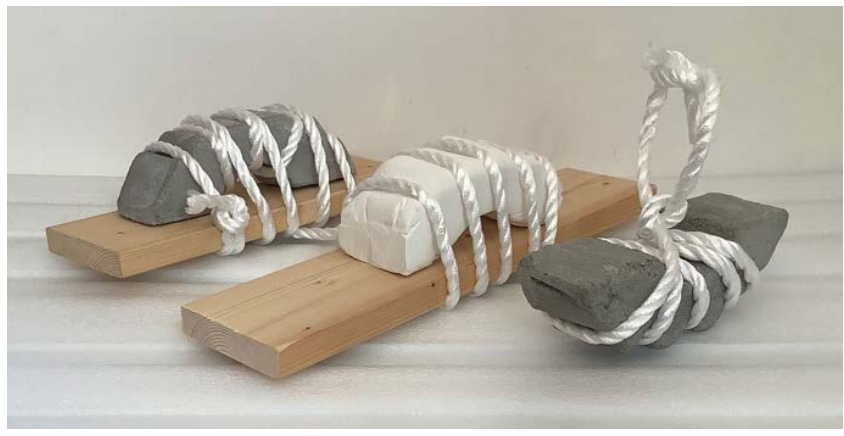

Figure 27. Arched rockers attached to timbers, and an example of passing a rope around the arched rocker (right).

\section{Evolution about How to Move Stones}

As is well known, Queen Hatshepsut remarkably pioneered architectural techniques, and wooden rockers would be invented during her reign (c.1479-1458 $\mathrm{BC}$ ). The fact that 36 many wooden rockers as votive objects were excavated from foundation deposits of Hatshepsut (Arnold, 1991) indicates that the wooden rockers played an important role in the construction of building like Hatshepsut's Temple. We pointed out in (Kato, 2020) that, in moving a stone, "rolling" is much easier than "dragging," and proposed various ways to move a heavy stone using ropes. Solid rockers produced by the wooden rocker transform cubic stone or octagonal column into the form of cylinder as in Figure 10 and Figure 11, evolving the way of moving heavy stones. A typical method pro- 
posed in (Kato, 2020) is to roll a stone as described in (1) of Figure 28 (see also Figure 8), where one end of each rope is held by some anchoring post and its other end is pulled. (Figure 28 is a side view so that only one thick rope is illustrated in each of (1) and (2), but actually, many ropes would be used.) Here, rockers made of stone as in Figure 7 were used, and we assumed such a method was already employed in the Pyramid Age, a millennium before Hatshepsut. Solid rockers with grooves would have evolved the way (1) into the way (2) of Figure 28, where the lower part of the rope is held by the grooved rocker so that we can dispense with any post as in (1). The rolling of (2) would be quite effective and much smoother than that of (1).

(1)

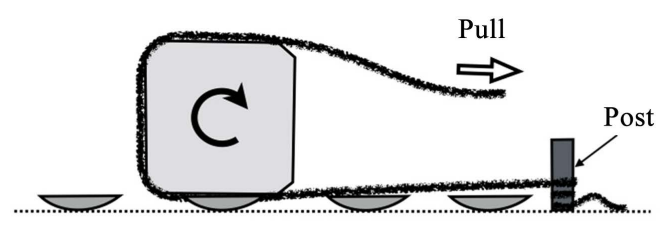

(2)

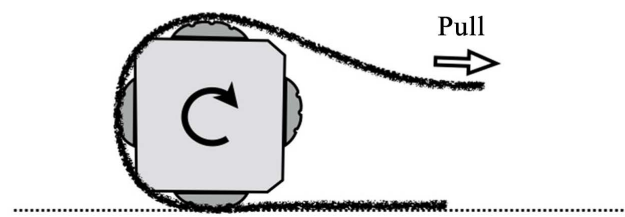

Figure 28. How to roll a heavy stone effectively by ropes: (1) Before Hatshepsut; (2) After Hatshepsut (Side view).

We also want to note about rolling stones of cylinder as we can see many many columns in temples of ancient Egypt, including Hatshepsut's Temple. Of course, physically no problem in rolling such stones, but suppose they were already decorated. Then we need special care to protect their surface. We already showed how to affix rockers to any flat surface of stone or sledge. Here, we want to propose that an arched rocker can be attached also to the stone of cylinder if its concave part (see Figure 21) is made to fit the surface of the cylinder like Figure 29. This way of Figure 29 surely can protect the surface of the cylinder, and so, would be actually employed frequently in rolling decorated columns.

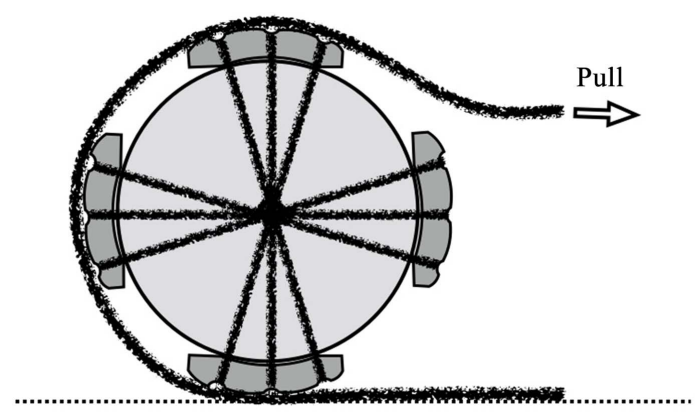

Figure 29. Arched rockers can be attached to a stone of cylinder if their concave parts were made to fit well onto the surface of the stone (Side view). 
The above evolution of moving stones, generated by rockers, took place, we believe, during Hatshepsut's reign, but it seems the wooden rockers soon faded into the background of history after Hatshepsut. Why? We do not know yet its true reason. What we can suspect is that:

1) The wooden rocker was kept being a useful tool in producing solid rockers even after Hatshepsut, but later pharaohs were hostile to Queen Hatshepsut so they did not include wooden rockers in their votive objects (Roehrig, 2005).

2) some alternative new device was invented utilizing some kind of "wheel" since the technology about wheel was introduced and developed remarkably during the New Kingdom era (c.1550-c.1069 BC), as symbolized by the "Chariots" of Egypt's military.

\section{Conclusions}

We proposed our new idea that the excavated wooden rockers are open mould to produce solid rockers, and this idea naturally stemmed from our former papers, (Kato, 2020) and (Kato, 2021), where "rocker made of stone" was introduced as one of important means to maneuver heavy stones. Seeking an alternative way of making it, rather than chamfering from a stone, we got the idea of moulding mudbrick or concrete rocker. In literatures there appeared various theories about how to use the wooden rockers: See (Arnold, 1991): Figure 6.29, Figure 6.30, (Clarke \& Engelbach, 1930), (Isler, 2001), (Petrie, 1910). But, it seems none of them meets the fact that the excavated wooden rockers look too fragile to be endured under a heavy stone. Our idea of "mould" obviously resolves this problem of fragility, excluding the idea of "models." And it should be recalled that the ancient Egyptians in the New Kingdom already had rich experience in making mudbricks and in using their concrete so that they had no difficulties in producing solid rockers using clay or concrete.

We hope this article has "excavated" a milestone in the evolution of ancient Egyptian's technique of maneuvering stones.

\section{Conflicts of Interest}

The author declares no conflicts of interest regarding the publication of this paper.

\section{References}

Arnold, D. (1991). Building in Egypt: Pharaonic Stone Masonry. Oxford: Oxford University Press.

Arooz, F. R., \& Halwatuna, R. U. (2018). Mud-Concrete Block (MCB): Mix Design and Durability Characteristics. Case Studies in Construction Materials, 8, 39-50. https://doi.org/10.1016/j.cscm.2017.12.004

Clarke, S., \& Engelbach, R. (1930). Ancient Egyptian Mansonry. London: Oxford University Press.

Fonte, A. (1998). Building the Great Pyramid in a Year. London: Professional Engineering Publishing. 
Hassaan, G. A. (2017). Mechanical Engineering in Ancient Egypt, Part 52: Mud-Bricks Industry, International Journal of Advanced Research in Management, Architecture, Technology and Engineering, 3, 11-16.

Isler, M. (2001). Sticks, Stones, and Shadows Building the Egyptian Pyra-Mids. Norman: University of Oklahoma Press.

Kato, A. (2020). How They Moved and Lifted Heavy Stones to Build the Great Pyramid. Archaeological Discovery, 8, 47-62. https://doi.org/10.4236/ad.2020.81003

Kato, A. (2021). How Obelisks Were Constructed, Moved, Shaped, and Erected in the Ancient Egypt. Archaeological Discovery, 9, 16-51. https://doi.org/10.4236/ad.2021.91002

Maspero, G., \& Edwards, A. B. (1895). Manual of Egyptian Archaeology and Guide to the Study of Antiquities in Egypt. New York: G. P. Putnam.

http://www.gutenberg.org/ebooks/14400

Petrie, W. M. F. (1910). Arts and Crafts of Ancient Egypt (The World of Art Series). Chicago, IL: A.C. McClurg. https://doi.org/10.5479/sil.247614.39088000358044

Pierattini, A. (2019). Interpreting Rope Channels: Lifting, Setting and the Birth of Greek Monumental Architecture.

https://www.cambridge.org/core/journals/annual-of-the-british-school-at-athens/volu me/3E6722E2EC597146C692561286EAB4B0

Roehrig, C. H. (2005). Hatshepsut from Queen to Pharaoh. New York: Metropolitan Museum of Art. 